\title{
CTX-M-32 beta-lactamase-producing uropathogenic Escherichia coli isolated in Latin America
}

\author{
María Araque ${ }^{1}$, Beatriz Millán ${ }^{1}$, Evelin Mendoza $^{2}$, Marianella Salas $^{2}$ \\ ${ }^{1}$ Laboratorio de Microbiología Molecular, Departamento de Microbiología y Parasitología, Facultad de Farmacia y \\ Bioanálisis, Universidad de Los Andes, Mérida, Venezuela \\ ${ }^{2}$ Laboratorio de Microbiología y Salud Pública del estado Mérida, Venezuela
}

Key words: extended-spectrum beta-lactamases; CTX-M-32; uropathogenic Escherichia coli; Latin America

J Infect Dev Ctries 2013; 7(5):432-435. doi:10.3855/jidc.3488

(Received 03 March 2013 - Accepted 13 April 2013)

Copyright (C) 2013 Araque et al. This is an open-access article distributed under the Creative Commons Attribution License, which permits unrestricted use, distribution, and reproduction in any medium, provided the original work is properly cited.

\section{Background}

Uropathogenic Escherichia coli (UPEC) is the most important pathogen involved in urinary tract infections (UTIs). Beta-lactam antibiotics have been widely used to treat UPEC infections; however, extended-spectrum beta-lactamases (ESBLs) create significant therapeutic problems by inactivating almost all beta-lactams except cephamycins and carbapenems $[1,2]$. The CTX-M-type beta-lactamases are members of a lineage of ESBLs currently recognized as the most widespread worldwide, both in clinical and community settings. Based on their amino-acid sequence diversity, more than 135 of the CTX-M identified variants have been classified into six major clusters: CTX-M-1, $-2,-8,-9,-25$ and -45 . (www.lahey.org/studies/webt.stm) [3-5]. These betalactamases predominantly hydrolyze cefotaxime (or ceftriaxone) but are weakly active against ceftazidime. However, to date the CTX-M-1 cluster is the most diversified group and includes more efficient CTX-M variants with a strong hydrolytic activity against ceftazidime, as is the case for CTX-M-32 [6]. In 2004, bla $_{\text {CTX-M-32 }}$ was first reported in an E. coli isolate from Spain [7]. Since then, CTX-M-32 continues to spread mainly in Mediterranean countries [3]. In Latin America, the prevalence of CTX-M beta-lactamases is represented by the CTX-M-2, but other variants such as CTX-M-1, CTX-M-8, CTX-M-9, CTX-M-12, CTX-M-14, CTX-M-15, CTX-M-16, CTX-M-24 and CTX-M-56 have been identified in this continent $[4,8]$. In this report, we describe the first detection of CTXM-32 in uropathogenic Escherichia coli from
Venezuela, which is also the first report of this enzyme in Latin America.

\section{The study}

In September 2011, a 46-year-old male diabetic patient was hospitalized in the internal medicine longstay unit service of University of The Andes Hospital (Mérida, Venezuela) with a history of recurrent urinary tract infection (UTI). This patient had more than three microbiologically documented episodes of symptomatic UTI during the last 6 months. Initially, the patient was managed with empirical first-line antibiotic therapy (amoxicillin or cephalexin) and later with wide-spectrum cephalosporins (ceftriaxone or cefotaxime). One cephalosporin-resistant strain of $E$. coli LMM23/11 was isolated from a urine sample at the Public Health Laboratory.

The strain was identified using conventional biochemical tests and confirmed using the API 20E system (bioMérieux, Marcy l'Etoile, France). Antimicrobial susceptibility testing was performed using the agar dilution method according to the recommendations of the CLSI guidelines [9]. This isolate showed a multidrug resistance phenotype including third-generation cephalosporins, gentamicin, tobramycin and ciprofloxacin, but was susceptible to carbapenems, tigecycline and colistin. ESBLs activity was confirmed by restoring susceptibility to cefotaxime and ceftazidime in the presence of clavulanic acid and also by the double-disk synergy test (Table 1). Few data are available on the role of diabetes mellitus itself as a risk factor for the development of antimicrobial resistance of 
Table 1. Antibiotic susceptibility of ESBL-producing E. coli LMM23/11 and transconjugants LMM23/11Tc

\begin{tabular}{|c|c|c|c|c|}
\hline \multirow[b]{2}{*}{$\begin{array}{l}\text { Antibiotics } \\
\text { tested }\end{array}$} & \multicolumn{4}{|c|}{ MIC (mg/liter) for } \\
\hline & $\begin{array}{c}\text { E. coli } \\
\text { LMM23/11 }\end{array}$ & $\begin{array}{c}\text { E. coli } \\
\text { LMM23/11Tc }\end{array}$ & $\begin{array}{c}\text { E. coli } \\
\text { MKD135 }\end{array}$ & $\begin{array}{c}\text { E. coli } \\
\text { ATCC } 25922 \\
\end{array}$ \\
\hline Cefoxitin & 8 & 8 & 4 & 2 \\
\hline Cefotaxime & $>256$ & 128 & 0.064 & 0.125 \\
\hline Cefotaxime/clavulanic acid ${ }^{\mathrm{a}}$ & 0.25 & 0.25 & 0.125 & 0.125 \\
\hline Ceftazidime & $>256$ & 64 & 0.025 & 0.25 \\
\hline Ceftazidime/clavulanic acid ${ }^{\mathrm{a}}$ & 0.25 & 0.25 & 0.25 & 0.125 \\
\hline Aztreonam & 4 & 4 & 0.25 & 0.25 \\
\hline Imipenem & 0.064 & 0.064 & 0.064 & 0.064 \\
\hline Ertapenem & 0.064 & 0.064 & 0.032 & 0.032 \\
\hline Meropenem & 0.064 & 0.064 & 0.064 & 0.032 \\
\hline Gentamicin & $>64$ & 32 & 0.5 & 0.5 \\
\hline Amikacin & 8 & 4 & 0.5 & 1 \\
\hline Tobramycin & 16 & 4 & 0.125 & 0.5 \\
\hline Ciprofloxacin & 8 & 0.125 & 0.25 & 0.0125 \\
\hline Colistin ${ }^{\mathrm{b}}$ & 1 & 0.5 & 0.25 & 0.25 \\
\hline Tigecycline $^{\mathrm{b}}$ & 0.25 & 0.125 & 0.125 & 0.032 \\
\hline Other test & & & & \\
\hline $\operatorname{DDST}^{\mathrm{c}}$ & + & + & - & - \\
\hline
\end{tabular}

uropathogens. However, recurrent infections are of particular concern because of the repeated morbidity and necessity for frequent administration of antibiotics, with the possible adverse selection consequences of antimicrobial-resistant strains [2]. The patient was treated according to the susceptibility test with i.v. meropenem.

E. coli LMM23/11 was submitted to the Molecular Microbiology Laboratory of The Andes University for confirmation of unusual resistance to wide-spectrum cephalosporins, determination of resistance mechanisms, characterization, and additional testing.

Detection of antimicrobial resistance $b l a_{\text {СТХ-M }}$ and bla $a_{\text {СТХ-M-1 }}$ genes was performed by PCR amplification using conditions previously described [10] and the following sets of primers: CTX-M-GF 5'ATGTGCAGYACCAGTAARGTKATGGC-' 3 and CTX-M-GR 5'CCGCTGCCGGTYTTATCVCCBAC-`3 for bla $a_{\text {CTX-м; }}$; CTX-M-1F 5`- GGTTAAAAAATCACTGCGTC-`3 and CTX-M-1R 5'-TTGGTGACGATTTTAGCCGC' 3 for $b l a_{\text {СТХ-M-1. }}$. The presence of other beta-lactamase genes was determined by previously described primers [11] with negative results. Amplification products were purified (PCR-Accuprep kit Bioneer). Nucleotide and amino acid sequence alignments, analyzed using the Basic Local Alignment Search Tool (BLAST) suite of programs (http://www.ncbi.nlm.nih.gov), revealed the presence of the $b l a_{\mathrm{CTX}-\mathrm{M}-32}$ gene, with a $98 \%$ degree of identity corresponding to the nucleotide sequence reference GenBank accession No AJ557142.

Conjugation studies were performed to determine if ESBLs could be transferred from $E$. coli LMM23/11 to E. coli MKD135 (Rifampicin). Transconjugants obtained were selected on Mueller Hinton Agar II plates (Becton Dickinson and Co., Sparks, MD, USA) containing rifampicin (400 mg/liter) and cefotaxime (2 $\mathrm{mg} /$ liter) as required. Transconjugants (LMM23/11Tc) showed the ESBL phenotype, as determined by MICs and positive PCR results for $b l a_{\text {CTX-M. }}$.

E. coli LMM23/11 was classified as belonging to the B2 phylogenetic group by a multiplex PCR assay using a combination of three DNA markers (chuA, $y j a A$ and the DNA fragment TspE4.C2) as described elsewhere [12]. It is generally accepted that the capacity of UPEC to cause disease among humans varies according to the presence and type of virulence factors within each lineage. However, other studies report that bacterial pathogens that acquire resistance determinants and express a multiresistant phenotype 
also show a reduced virulence [13]. Four of the six virulence genes (usp, fyuA, KpsMTII and fim $\mathrm{H}$ ), detected by PCR using specific primers as described previously [14], underline the possible emergence of a highly virulent multiresistant strain in Venezuela (Table 2).

\section{Conclusion}

We report the presence of the bla $_{\mathrm{CTX}-\mathrm{M}-32}$ gene in uropathogenic Escherichia coli from a diabetic patient in Venezuela and, to our knowledge, this provides the first description of a CTX-M-32 beta-lactamase in Latin America. A few CTX-M-32-producing strains have been isolated from clinical samples in Spain, Italy, Greece and Portugal, suggesting the existence of community reservoirs for CTX-M enzymes and an ongoing widespread dissemination in the Mediterranean area [3,5,12].

In terms of evolution, CTX-M-3 was likely the enzyme at the origin of diversification in the CTX-M1 cluster, which was coincident with positive selection acting on several amino acid positions $[6,15]$. Analysis of sequencing, showing that CTX-M-32 differs from CTXM-1 by a single Asp240-Gly substitution, is a key factor in the evolution of CTX-M beta-lactamases for its increased level of resistance to ceftazidime. As a matter of fact, our bla $a_{\mathrm{CTX}-\mathrm{M}-32 \text {-containing } E \text {. coli }}$ LMM23/11 strain showed a ceftazidime high MIC value ( $>256 \mathrm{mg} /$ liter).

The results obtained suggest that the E. coli LMM23/11 expressing CTX-M-32 is a potent uropathogenic strain belonging to the phylogenetic group B2. This strain can efficiently colonize the intestine because of the presence of virulence factors that subsequently might infect the urinary tract, regardless of its selection as a result of antibiotic

Table 2. Genetic characteristics of uropathogenic E. coli LMM23/11

\begin{tabular}{cc}
\hline Characteristic & E. coli $\mathrm{LMM} 23 / 11$ \\
\hline beta-lactamase & - \\
bla $a_{\mathrm{TEM}}$ & - \\
bla $a_{\mathrm{SHV}}$ & $+(\mathrm{CTX}-\mathrm{M}-32)$ \\
bla $\mathrm{CTX}-\mathrm{M}$ & + \\
\hline Virulence factors & + \\
fimH & + \\
fyuA $\mathrm{II}$ & + \\
usp & - \\
papAH & - \\
PAI & $\mathrm{B} 2$
\end{tabular}

pressure. We hope that these findings will contribute to the knowledge of the population genetic structure of UPEC and their propensity to spread, or emerge, with multidrug resistant phenotypes in developing countries.

\section{Acknowledgements}

This study was partially supported by the Council of Scientific, Humanistic and Technological Development of University of The Andes (CDCHTA-ULA), Mérida,Venezuela (grant CVI-ADG-FA-02-97).

We would like to extend our thanks to Dr. Silvana Vielma (Coordinator of Public Health Laboratory, Mérida, Venezuela) and Dr. Saberio Pérez Lopresti for collaboration at the initial stage of this study.

\section{References}

1. Vimont S, Boyd A, Bleibtreu A, Bens M, Goujon JM, Garry L, Clermont O, Denamur E, Arlet G, Vandewalle A (2012) The CTX-M-15-producing Escherichia coli clone 025b:H4ST131 has high intestine colonization and urinary tract infection abilities. PLoS One 7: e0046547.

2. Jadhav S, Hussain A, Devi S, Kumar A, Parveen S, Gandham N, Wieler LH, Ewers C, Ahmed N (2011) Virulence characteristics and genetic affinities of multiple drug resistant uropathogenic Escherichia coli from a semi urban locality in India. PLoS One 6: e0018063.

3. Cantón R, González-Alba JM, Galán JC (2012) CTX-M enzymes: origin and diffusion. Front Microbiol 3: 2012.00110 .

4. Sennati S, Santella G, Di Conza J, Pallecchi L, Pino M, Ghiglione B, Rossolini GM, Radice M, Gutkind G (2012) Changing epidemiology of extended-spectrum $\beta$-lactamase in Argentina: emergence of CTX-M-15. Antimicrob Agents Chemother 56: 6003-6005.

5. Novais A, Comas I, Baquero F, Cantón R, Coque TM, Moya A, González-Candelas F, Galán JC (2010) Evolutionary trajectories of beta-lactamase CTX-M-1 cluster enzymes: predicting antibiotic resistance. PLoS Pathog 6: e1000735.

6. Rossolini GM, D'Andrea MM, Mugnaioli C (2008) The spread of CTX-M-type extended-spectrum $\beta$-lactamases. Clin Microb Infect 14: 33-41.

7. Cartelle M, Tomas MM, Molina F, Moure R, Villanueva R, Bou G (2004) High-level resistance to ceftazidime conferred by a novel enzyme, CTX-M-32, derive from CTX-M-1 through a single Asp240-Gly substitution. Antimicrob Agents Chemother 48: 2308-2313.

8. Villegas MV, Kattan JN, Quinteros MG, Casellas JM (2008) Prevalence of extended-spectrum $\beta$-lactamases in South America. Clin Microbiol Infect 14: 154-158.

9. Clinical and Laboratory Standards Institute (2012) Performance standards for antimicrobial susceptibility testing, 22th informational supplement. CLSI Document M100-S22. Wayne, PA.

10. Eckert C, Gautier V, Arlet G (2006) DNA sequence analysis of the genetic environment of various blaCTX-M genes. J Antimicrob Chemother 57: 14-23. 
11. Mugnaioli C, Luzzaro F, De Luca F, Brigante G, Perilli G, Amicosante G, Stefani S, Toniolo A, Rossolini GM (2006) CTX-M-type extended-spectrum $\beta$-lactamases in Italy: molecular epidemiology of an emerging countrywide problema. Antimicrob Agents Chemother 50: 2700-2706.

12. Clermont O, Bonacorsi S, Bingen E (2000) Rapid and simple determination of the Escherichia coli phylogenetic group. Appl Envirom Microbiol 66: 4555-4558

13. Molina-López J, Aparicio-Ozores G, Ribas-Aparicio RM, Gavilanes-Parra S, Chávez-Berrocal ME, Hernández-Castro R, Manjarrez-Hernández HA (2011) Drug resistance, serotypes, and phylogenetic groups among uropathogenic Escherichia coli including O25-ST131 in Mexico City. J Infect Dev Ctries 5: 840-849.

14. Johnson JR, Stell A (2000) Extended virulence genotypes of Escherichia coli strains from patients with urosepsis in relation to phylogeny and host compromise. J Infect Dis 181: 261-272.

15. Fernández A, Gil E, Cartelle M, Pérez A, Beceiro A, Mallo S, Tomás MM, Pérez-Llarena FJ, Villanueva R, Bou G (2007) Interspecies spread of CTX-M-32 extended-spectrum $\beta$ lactamase and the role of the insertion sequence IS1 in downregulating $b l a_{\text {СТХ-M }}$ gene expression. J Antimicrob Chemother 59: 841-847.

\section{Corresponding author}

María Araque

Laboratorio de Microbiología Molecular

Departamento de Microbiología y Parasitología

Facultad de Farmacia y Bioanálisis

Universidad de Los Andes, Sector Campo de Oro

Mérida 5101, Venezuela

Telephone/Fax: +58-274-2403180

Email: araquemc@ula.ve

Conflict of interests: No conflict of interests is declared. 